DOI: $10.5902 / 198468628229$

\title{
Surdez com recorte racial: estado da arte no Brasil de 2012- 2017
}

\author{
Deafness with racial clipping: state of art in Brazil 2012-2017
}

Sordera con recorte racial: estado del arte en Brasil de 2012-2017

\begin{abstract}
* Viviane Marques Miranda
Mestranda na Universidade Nove de Julho (UNINOVE), São Paulo, São Paulo, Brasil. vivi_starpop@yahoo.com.br
\end{abstract}

Recebido: 23 de julho de 2017

Aprovado: 5 de janeiro de 2018

\section{RESUMO}

Este artigo apresenta os resultados de um estudo quantitativo-descritivo de pesquisas realizadas no Brasil, circunscritas ao período de 2012 a 2017, acerca do recorte racial nos estudos da área da surdez, com a busca realizada na Biblioteca Digital de Teses e Dissertações (BDTD), tendo como palavras-chave: surdez e raça. A fim de analisar o corpus encontrado, foram definidas as seguintes categorias: (i) modalidade de produções, (ii) produções acadêmicas por universidade, (iii) área de concentração, (iv) tipos de pesquisas (v) referenciais teóricos relacionados a surdez e raça. Destaca-se que, no período, foram defendidas 3 dissertações de mestrado na área de concentração de Educação, nas seguintes instituições: UnB, UFRGS e UEL, respectivamente de Buzar (2012), Furtado (2012) e Vedoato (2015). Esta desenvolve abordagem quantitativa com pesquisa documental e aqueles trazem, basicamente, abordagem qualitativa com uso de entrevistas. Os referenciais teóricos das pesquisas alinham-se aos Estudos Culturais. Conclui-se que é necessário conhecer o que já foi feito e produzido para que novos estudos sejam realizados, podendo assim ampliar a área não só em termos de quantidade, mas também de rigor teórico e metodológico.

Palavras-chave: Surdez; Recorte racial; Estado da arte.

\section{ABSTRACT}

This article presents the results of a quantitative-descriptive study of Brazilian studies, limited to the period from 2012 to 2017, about the racial cut in the studies of the deafness area, with the search carried out at the Digital Library of Theses and Dissertations (BDTD) having as key words: deafness and race. In order to analyze the corpus found, the following categories were defined: (i) production modality, (ii) academic productions per university, 
DOI: $10.5902 / 198468628229$

(iii) concentration area, (iv) types of research (v) theoretical references related to deafness and race. It is worth noting that 3 dissertations were held in the area of Education concentration in the following institutions: UnB, UFRGS and UEL, respectively from Buzar (2012), Furtado (2012) and Vedoato (2015). This develops quantitative approach with documentary research and those bring, basically, qualitative approach using interviews. The theoretical references of the researches are aligned with the Cultural Studies. It is concluded that it is necessary to know what has already been done and produced so that new studies can be carried out, thus expanding the area not only in terms of quantity, but also of theoretical and methodological rigor.

Keywords: Deafness; Racial cut; State of art.

\section{RESUMEN}

Este artículo presenta los resultados de un estudio cuantitativo-descriptivo de investigaciones realizadas en Brasil, circunscritas al período de 2012 a 2017, acerca del recorte racial en los estudios del área de la sordera, con la búsqueda realizada en la Biblioteca Digital de Tesis y Disertaciones (BDTD) , teniendo como palabras clave: sordera y raza. (li) producciones académicas por universidad, (iii) área de concentración, (iv) tipos de investigaciones $(v)$ referenciales teóricos relacionados a sordera, a fin de analizar el corpus encontrado, se definieron las siguientes categorías: (i) modalidad de producciones, (ii) producciones académicas por universidad, (iii) área de concentración, (iv) tipos de investigación (v) y la raza. Se destaca que, en el período, se defendieron 3 disertaciones de maestría en el área de concentración de Educación, en las siguientes instituciones: UnB, UFRGS y UEL, respectivamente de Buzar (2012), Furtado (2012) y Vedoato (2015). Esta desarrolla abordaje cuantitativo con investigación documental y aquellos traen, básicamente, abordaje cualitativo con el uso de entrevistas. Los referenciales teóricos de las encuestas se alinean con los Estudios Culturales. Se concluye que es necesario conocer lo que ya se ha hecho y producido para que nuevos estudios sean realizados, pudiendo así ampliar el área no sólo en términos de cantidad, sino también de rigor teórico y metodológico.

Palabras clave: Sordera; Recorte racial; Estado del arte.x; y; z.

\section{Introdução}

O desafio deste trabalho consiste em mapear a produção acadêmica referente ao entrecruzamento das categorias surdez e raça, circunscrita ao período de 2012 a 2017 no 


\section{DOI: $10.5902 / 198468628229$}

Brasil. Esta demarcação deve-se ao fato de que a primeira pesquisa pertinente localizada data de 2012.

As ações coletivas do movimento social surdo no Brasil, do período de 1990-2000, segundo Brito (2013), estavam envolvidas, sobretudo, na campanha pela oficialização da língua de sinais como demanda principal do movimento. Sendo assim, a promulgação da Lei no 10.436 em 2002 garantiu a possibilidade de a identidade coletiva surda organizar-se entorno de uma língua comum e em 2005, o Decreto $n^{\circ} 5.626$ vem a regulamentar a referida Lei. Tais fatos podem ter convergido para a emergência de demandas identitárias além da língua - primeiro no âmbito da militância e, posteriormente, no da academia. Dessa forma, em 2008, após o reconhecimento da LIBRAS $^{1}$ como meio legal de comunicação e expressão dos surdos brasileiros, começam em São Paulo as primeiras discussões (de que se têm notícia até o momento) acerca da inclusão social do negro surdo, organizadas no interior do movimento social surdo paulistano.

O movimento surdo com recorte racial passa em alguns anos de um evento localizado e pontual a um movimento nacional organizado formalmente, conforme é possível conferir na tabela abaixo:

Tabela 1 - Movimento Inclusão Social do Negro Surdo

\begin{tabular}{|c|c|c|c|c|c|c|}
\hline 은 & $\begin{array}{c}\text { Palestra } \\
\text { Inclusão } \\
\text { Social do } \\
\text { Negro Surdo }\end{array}$ & $\begin{array}{l}\text { Il Congresso } \\
\text { Nacional de } \\
\text { Inclusão } \\
\text { Social do } \\
\text { Negro Surdo }\end{array}$ & $\begin{array}{l}\text { IIl Congresso } \\
\text { Nacional de } \\
\text { Inclusão } \\
\text { Social do } \\
\text { Negro Surdo }\end{array}$ & $\begin{array}{c}\text { IV } \\
\text { Congresso } \\
\text { Nacional de } \\
\text { Inclusão } \\
\text { Social do } \\
\text { Negro Surdo }\end{array}$ & $\begin{array}{l}\text { V Congresso } \\
\text { Nacional de } \\
\text { Inclusão } \\
\text { Social do } \\
\text { Negro Surdo }\end{array}$ & $\begin{array}{c}\text { VI Congresso } \\
\text { Nacional de } \\
\text { Inclusão Social do } \\
\text { Negro Surdo }\end{array}$ \\
\hline $\begin{array}{l}\frac{1}{4} \\
0 \\
0\end{array}$ & $\begin{array}{c}\text { DERDIC } \\
\text { Divisão de } \\
\text { Educação e } \\
\text { Reabilitação } \\
\text { dos Distúrbios } \\
\text { da } \\
\text { Comunicação }\end{array}$ & $\begin{array}{l}\text { Memorial da } \\
\text { América Latina }\end{array}$ & $\begin{array}{c}\text { Museu Afro } \\
\text { Brasil }\end{array}$ & $\begin{array}{c}\text { UNEB } \\
\text { Universidade } \\
\text { do Estado } \\
\text { da Bahia }\end{array}$ & $\begin{array}{c}\text { ISERJ } \\
\text { Instituto } \\
\text { Superior de } \\
\text { Educação do } \\
\text { Rio de } \\
\text { Janeiro }\end{array}$ & $\begin{array}{c}\text { UFSC } \\
\text { Universidade } \\
\text { Federal de Santa } \\
\text { Catarina }\end{array}$ \\
\hline
\end{tabular}

\footnotetext{
${ }^{1}$ Língua Brasileira de Sinais.
} 
DOI: 10.5902/198468628229

\begin{tabular}{|c|c|c|c|c|c|c|}
\hline $\begin{array}{l}\text { 㟔 } \\
\text { 号 }\end{array}$ & São Paulo-SP & São Paulo-SP & São Paulo-SP & Salvador-BA & $\begin{array}{c}\text { Rio de } \\
\text { Janeiro-RJ }\end{array}$ & Florianópolis-SC \\
\hline 高 & 2008 & 2009 & 2012 & 2013 & 2015 & 2017 \\
\hline 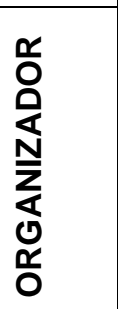 & $\begin{array}{c}\text { Sandro dos } \\
\text { Santos } \\
\text { Pereira }\end{array}$ & $\begin{array}{c}\text { Sandro dos } \\
\text { Santos Pereira }\end{array}$ & $\begin{array}{c}\text { Sandro dos } \\
\text { Santos Pereira }\end{array}$ & $\begin{array}{c}\text { Sandro dos } \\
\text { Santos } \\
\text { Pereira }\end{array}$ & $\begin{array}{c}\text { Sem } \\
\text { informação }\end{array}$ & Sem informação \\
\hline 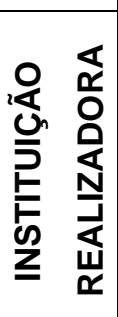 & CBS & CBS & $\begin{array}{c}\text { Sem } \\
\text { informação }\end{array}$ & FENEIS & FENEIS & FENEIS \\
\hline
\end{tabular}

Fonte: Elaboração própria (2018)

Figura 1 - Certificado da palestra Inclusão Social do Negro Surdo

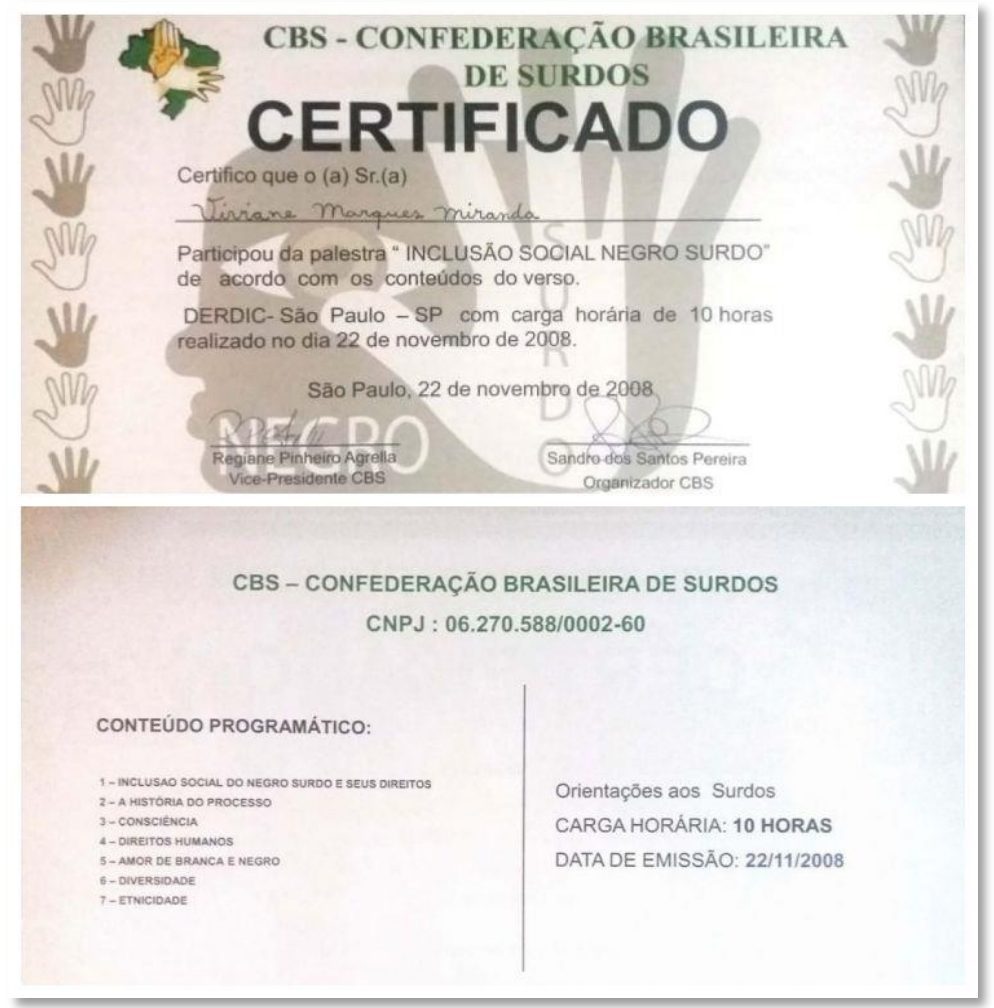

Fonte: Elaboração própria (2018) 
Portanto, de 2008, data do primeiro evento constituído a partir dos eixos surdez e raça, transcorre um, relativamente, curto espaço de tempo para o desenvolvimento dos primeiros trabalhos acadêmicos pertinentes ao tema, em 2012. Anterior a essa demarcação não foram encontradas pesquisas relevantes com o enfoque racial na área da surdez.

A principal plataforma de pesquisa foi a Biblioteca Digital de Teses e Dissertações (BDTD) que integra os sistemas de informação de teses e dissertações existentes nas instituições de ensino e pesquisa brasileiras; além de periódicos eletrônicos da área da educação e da surdez. A partir dos trabalhos localizados, suas referências bibliográficas foram utilizadas para investigação de outras pesquisas que abordassem o assunto. Além disso, a consulta ao Currículo Lattes dos orientadores e dos autores das pesquisas foi realizada, rigorosamente, a fim de levantar outros trabalhos com esse viés, nos quais, porventura, os pesquisadores estivessem envolvidos.

A fim de analisar o corpus encontrado, foram definidas as categorias: (i) modalidade de produções, (ii) produções acadêmicas por universidade, (iii) área de concentração, (iv) tipos de pesquisas (v) referenciais teóricos relacionados a surdez e raça. Destaca-se que, no período, foram defendidas 3 dissertações de mestrado na área de concentração de Educação, nas seguintes instituições: $U_{n B}^{2}$, UFRGS ${ }^{3}$ e $U^{2} L^{4}$, respectivamente de Francisco José Roma Buzar (2012), Rita Simone Silveira Furtado (2012) e Sandra Cristina Malzinoti Vedoato (2015). Esta desenvolve abordagem quantitativa com pesquisa documental e aqueles trazem, basicamente, abordagem qualitativa com uso de entrevistas. Os referenciais teóricos das pesquisas alinham-se aos Estudos Culturais.

Este mapeamento demonstra sua importância por revelar a escassez de estudos que explorem o entrecruzamento de surdez e raça em um país cuja população negra, especificamente no grupo de pessoas com deficiência auditiva, conforme o último Censo do IBGE $^{5}$ (2010), tem se revelado expressiva. Além disso, intenta divulgar tais estudos a fim de, quiçá, despertar interesse em uma área que pode ser promissora para mais explorações em pesquisas futuras.

\footnotetext{
2 Universidade de Brasília.

3 Universidade Federal do Rio Grande do Sul.

4 Universidade Estadual de Londrina.

5 Instituto Brasileiro de Geografia e Estatística.
} 


\section{Alguns trabalhos anteriores}

DOI: $10.5902 / 198468628229$

No artigo Surdez, linguagem e cultura, Bueno (1998) precede o debate da surdez orientada pelo recorte racial, dentre outros, indicando, en passant, algumas questões que valem a pena ser pontuadas. Segundo ele, o multiculturalismo contrapõe-se a uma visão de cultura universalizante e uniformizadora. Além disso, diferenças como raça, classe e gênero são determinações fundamentais para as representações e para a diversidade cultural no multiculturalismo crítico. Sendo assim, a referência a uma cultura seria reflexo da dominação de determinados grupos sobre outros.

Bueno (1998) pontua que, em uma perspectiva multicultural, tem-se defendido a existência de uma cultura surda, presente em comportamentos, valores, atitudes, estilos cognitivos e práticas sociais diferentes da cultura ouvinte. Ocorrendo, por conseguinte, uma tendência de homogeneização das diferenças no que se denomina cultura ouvinte, dominadora, e cultura surda, dominada; sendo a surdez colocada em relevo, em prejuízo de diferenças como raça, classe ou gênero. Tal movimento acaba por produzir uma abstratização do surdo, visto que a surdez é apresentada como única característica determinante de sua identidade.

A consequência do reducionismo e da abstratização apontados é a produção de um novo paradigma de identidade, de uma nova hegemonia baseada em um ideal surdo: a emergência de uma identificação fundamentada na surdez e na língua de sinais, em detrimento de diferenças substanciais, que seriam desconsideradas. O encobrimento das diferenças pela busca de um novo padrão fundamentar-se-ia em um caráter fortemente ideológico. No entanto, Bueno (1998) questiona se:

[...] a surdez é suficiente para identificarmos dois sujeitos como uma mulher, negra, pobre, latino-americana, vivendo em pequena localidade rural e surda e um homem, branco, rico, europeu, vivendo em metrópole e surdo? Que a surdez é um traço de identificação entre eles não se nega. Mas isso é suficiente para considerá-los como "pares" ou como "iguais"? Eles fazem parte de uma mesma comunidade só pelo fato de serem surdos? (BUENO, 1998, [s.n.])

O autor afirma que determinações de raça, classe e gênero são importantes para a análise das culturas; sendo assim, considera relevante trazer essa discussão ao se tratar do surdo na perspectiva multicultural, correndo o risco de, em desconsiderando essas determinações, deturpar a origem teórica da própria perspectiva adotada. Finalmente, Bueno (1998) considera que é necessário entender os impactos sociais causados pela 


\section{DOI: $10.5902 / 198468628229$}

surdez, ao lado das determinações de classe, raça e gênero, para que se possa avançar no sentido de contribuir efetivamente para o acesso à cidadania.

A discussão proposta por Bueno (1998) foi um dos poucos referenciais localizados acerca da temática nos anos 90, no Brasil. Desse período, ainda merecem menção dois autores: Dorziat e Skliar. Este (em publicação de 1998, cuja 3ā edição data de 2005) observa que não são reconhecidos aos surdos os múltiplos recortes de identidade, cultura, comunidade e etnia. Adverte ainda do risco de, ocasionalmente, se falar desse grupo aludindo apenas aos surdos homens, brancos, de classe média, escolarizados e ativistas. No entanto, continua o autor, os surdos não constituem um grupo homogêneo em cujo interior se estabelecem processos sólidos de identificação e simetria de poder entre seus membros. Também fazem parte desse conjunto, os surdos das classes populares, os surdos que não sabem que são surdos, as mulheres surdas, os surdos negros, os surdos meninos de rua etc.

Dorziat (1999), que apesar de não desenvolver uma discussão sistemática sobre o assunto, pontua que a educação de surdos deve ser dimensionada para além de questões linguísticas e metodológicas; devendo ser perspectivada no âmbito das discussões da educação como um todo, levando em consideração o enfoque dos conflitos de classe, raça, gênero, dentre outros. Poder-se-ia mencionar ainda o artigo de Garcia (1999), que apesar de discutir o contexto norte-americano, aparece em uma publicação brasileira do final da década de 90, em que a autora pontua as tensões existentes no interior da comunidade surda americana, onde, segundo ela, a identidade surda seria considerada primária ou a única identidade relevante, em detrimento do recorte racial ou étnico.

Em 2005, na edição n 24 da Revista Espaço do INES ${ }^{6}$, Paixão publica um estudo no qual realiza uma análise minuciosa de dois indicadores sociais, sc: acesso ao mercado de trabalho e intensidade de pobreza e indigência na população com deficiência entre 15 e 65 anos, desagregados pela variável raça/cor, a partir de dados do Censo Demográfico de 2000, do IBGE. O estudo considerou negras as pessoas autodeclaradas pretas e pardas. O grupo de pessoas com deficiência foi dividido em: problema mental permanente, incapacidade de enxergar, incapacidade de ouvir, incapacidade de andar, alguma forma de paralisia, ausência de alguma parte do corpo, não apresenta nenhuma incapacidade relativa.

${ }^{6}$ Instituto Nacional de Educação de Surdos. 


\section{DOI: $10.5902 / 198468628229$}

O estudo (PAIXÃO, 2005) mostra que, apesar de existirem nítidas diferenças entre os indicadores analisados referentes às pessoas com deficiência comparativamente ao restante da população, as condições de vida daquelas conforme cor/raça seriam, razoavelmente, piores, refletindo as assimetrias verificadas na população em geral conforme a mesma variável. Com isso, pessoas com deficiência enfrentariam dificuldades agravadas de acesso ao espaço público, ao emprego e à representação política. Finalmente, Paixão (2005) considera que o modo de incidência das mazelas atuaria de forma qualitativamente diferenciada de acordo com o tipo de situação. Sendo assim, os movimentos anti-racistas e os movimentos de promoção da cidadania da pessoa com deficiência seriam parceiros estratégicos na luta por igualdade.

\section{Buzar, Furtado e Vedoato}

Os três trabalhos pertinentes localizados na BDTD são dissertações de mestrado acadêmico, concentradas na área da Educação, de universidades públicas da Região Sul e Centro-Oeste.

Buzar (2012), não obstante ter realizado sua pesquisa pela Universidade de Brasília, coletou seus dados em São Luís do Maranhão, estado onde realizou sua graduação em Ciências Sociais pela UFMA? ${ }^{7}$. Por ser casado com uma mulher negra, atuante tanto no mundo dos surdos quanto no mundo dos negros, conforme ele relata, foi apreendido pelo tema.

Furtado (2012) apresenta-se como uma mulher negra com deficiência física; formada em pedagogia, realizou uma pós-graduação lato sensu em Educação Especial, onde desenvolveu sua pesquisa na área da surdez e pode, a partir de suas vivências na condição de pessoa duplamente diferente, lobrigar seu objeto de pesquisa no mestrado.

Vedoato (2015) teve seus primeiros contatos com surdos em eventos religiosos no interior de São Paulo, onde vivia; fez curso de LIBRAS e passou a atuar com surdos. Casouse com uma pessoa surda e graduou-se em fonoaudiologia. Seu contato amiudado com surdos a fez observar "que a marca da surdez é o que os assemelha, mas, não os iguala" (VEDOATO, 2012, p. 14). E ao ingressar no mestrado, teve contato com referenciais teóricos como as análises de Bueno (1998), dentre outros, o que a aproximou do tema.

As três pesquisas localizadas podem ser conferidas na Tabela 2:

\footnotetext{
${ }^{7}$ Universidade Federal do Maranhão.
} 
Tabela 2 - Surdez com recorte racial (2012-2017)

\begin{tabular}{|c|c|c|c|}
\hline UNIVERSIDADE & UnB & UFRGS & UEL \\
\hline LOCAL & Brasília & Porto Alegre & Londrina \\
\hline REGIÃO & Centro-Oeste & Sul & Sul \\
\hline ANO & 2012 & 2012 & 2015 \\
\hline AUTOR & $\begin{array}{c}\text { Francisco José Roma } \\
\text { Buzar }\end{array}$ & $\begin{array}{c}\text { Rita Simone } \\
\text { Silveira Furtado }\end{array}$ & $\begin{array}{l}\text { Sandra Cristina } \\
\text { Malzinoti Vedoato }\end{array}$ \\
\hline TÍTULO & $\begin{array}{l}\text { Interseccionalidade entre } \\
\text { raça e surdez: a situação } \\
\text { de surdos (as) negros } \\
\text { (as) em São Luís-MA }\end{array}$ & $\begin{array}{c}\text { Narrativas } \\
\text { identitárias e } \\
\text { educação: os } \\
\text { surdos negros na } \\
\text { contemporaneidade }\end{array}$ & $\begin{array}{c}\text { Relações entre } \\
\text { surdez, raça e } \\
\text { gênero no processo } \\
\text { de escolarização de } \\
\text { alunos surdos do } \\
\text { Paraná }\end{array}$ \\
\hline $\begin{array}{l}\text { LINHA DE } \\
\text { PESQUISA }\end{array}$ & $\begin{array}{l}\text { Gênero, Raça e } \\
\text { Juventude }\end{array}$ & $\begin{array}{l}\text { Estudos Culturais } \\
\text { em Educação }\end{array}$ & Educação Especial \\
\hline PROGRAMA & Educação & Educação & Educação \\
\hline ORIENTADOR & Dr. ㄹ Denise Maria Botelho & $\begin{array}{l}\text { Dra. Lodenir Becker } \\
\text { Karnopp }\end{array}$ & $\begin{array}{l}\text { Drª . Silvia Márcia } \\
\text { Ferreira Meletti }\end{array}$ \\
\hline
\end{tabular}

Fonte: Elaborado pela autora (2018)

Buzar (2012) usa o conceito de interseccionalidade para falar da situação do surdo negro. Furtado (2012) chama de dupla diferença. Vedoato (2015) nomeia de marca concorrente ou de condição associada à surdez. Esta se fundamenta no entendimento de que a surdez é uma deficiência, com dimensões biológicas, culturais e sociais. Buzar (2012) e Furtado (2012) abordam a surdez sob um enfoque socioantropológico, ou seja, como uma diferença linguística e cultural. Quanto à raça, todos os autores trazem uma dimensão social e política para a compreensão do conceito e das desigualdades sociais a ele associadas. As metodologias dos trabalhos variam: Vedoato (2015) utiliza dados estatísticos; Buzar (2012) e Furtado (2012) utilizam basicamente entrevistas semi-estruturadas. Buzar (2012) 
DOI: $10.5902 / 198468628229$

entrevista surdos brancos e negros, dentre homens e mulheres, Furtado (2012) entrevista somente surdos negros, dentre homens e mulheres. Todos os autores colocam a surdez ou a deficiência como identidade primária: Buzar (2012) e Furtado (2012) falam do surdo negro; e Vedoato (2015) fala da pessoa surda segundo cor/raça.

Curiosamente, em pesquisas sobre surdos indígenas observa-se a predominância da designação étnica, primeiro, e, por último, a qualificação de surdo: indígena surdo, índio surdo, indígenas com deficiência, akwẽ-xerente surdos, embora haja ocorrências de surdo Kaingang, surdo indígena e surdo-índio, porém com menor frequência. A discussão acerca das possíveis razões dessas diferenças de predominância de registros (surdo negro e indígena surdo) foge ao escopo desta pesquisa. No entanto, sinalize-se para essa possibilidade de investigação.

\section{Interseccionalidade entre raça e surdez}

Em 2012, Buzar realiza uma pesquisa em nível de mestrado na área da Educação pela Universidade de Brasília, cujo título é Interseccionalidade entre raça e surdez: a situação de surdos negros em São Luís - MA. Por meio de entrevista semiestruturada com um grupo de trinta surdos, entre negros, morenos e brancos, frequentadores da Associação de Surdos do Maranhão (ASMA) na capital, o autor discute as circunstâncias concretas da experiência de intersecção vivenciada por surdos negros. A pesquisa foi realizada em janeiro de 2012, com um grupo de surdos, sendo doze do sexo feminino e dezoito do sexo masculino e todos acima de vinte anos de idade. A pesquisa agregou pessoas surdas negras e morenas na categoria negro, visto que os dois grupos, segundo Buzar (2012), apresentam proximidades quanto à exclusão racial.

O estudo analisa, a partir das narrativas dos entrevistados, de que modo a discriminação interseccional se configura em suas trajetórias, acadêmica e social; trazendo à tona a invisibilidade e a subordinação dessa condição singular nas comunidades surda e negra e principalmente nas políticas públicas. As análises utilizam o conceito de interseccionalidade e o referencial da Análise de Discurso Crítica.

O conceito de interseccionalidade é utilizado como ferramenta de análise. Segundo essa concepção, vulnerabilidades e subordinações são aumentadas quando há um cruzamento de identidades: racial, de gênero, de classe social etc. A superinclusão, derivada de contextos de interseccionalidade, consiste no fenômeno conforme o qual um 
DOI: $10.5902 / 198468628229$

grupo sofre vulnerabilidades específicas ou desproporcionais às sofridas por outra parte do grupo, apesar de interpretar-se como um problema geral. A abordagem subinclusiva, por sua vez, consiste na não identificação da vulnerabilidade por não atingir diretamente a maioria do grupo.

Sendo assim, o estudo enfoca a superinclusão de surdos negros, em que estes vivenciariam a surdez diferentemente dos surdos brancos. Entretanto, essa especificidade não estaria sendo abordada pelos estudos acerca da surdez ou seria abordada como uma vulnerabilidade comum à totalidade do grupo. Consequentemente, as condições específicas de discriminação seriam ignoradas, tanto no meio acadêmico, quanto nas políticas públicas.

Os dados coletados nas entrevistas foram organizados em duas categorias da Teoria da Interseccionalidade: discriminação interseccional e vulnerabilidades específicas, estas, por sua vez, subdividiram-se em outras categorias cada uma.

As vulnerabilidades específicas são constituídas por aspectos que fragilizam a experiência vivencial das pessoas surdas negras, e que são desproporcionais às vividas pelas demais pessoas surdas e pelas demais pessoas negras, acarretando invisibilidade nos movimentos surdos e nos movimentos negros, uma vez que a interseccionalidade entre raça e surdez não é abordada. Já a categoria da discriminação interseccional considera que surdos negros sofrem discriminação tanto por serem surdos quanto por serem negros. Dessa forma, os direitos dos surdos ficariam restritos apenas ao viés da deficiência, comprometendo, assim, o acesso a direitos já garantidos em outras áreas, como os avanços relacionados às questões raciais.

Durante as entrevistas, o déficit linguístico apresentado por mais da metade dos surdos negros entrevistados foi destacado, ocasionando dificuldades na comunicação; verificou-se combinação de LIBRAS com gestos ou conhecimento linguístico insuficiente, com respostas desconexas em relação às perguntas. Segundo Buzar (2012), para que se entendesse o que esses entrevistados gostariam de argumentar, houve necessidade de muitos ajustes na comunicação, como explicações da intérprete e discussões das respostas. Em contrapartida, todos os demais entrevistados apresentaram fluência em LIBRAS na comunicação com o pesquisador, fornecendo respostas coerentes ao que estava sendo perguntado. Sendo assim, Buzar (2012) conclui que os surdos negros de sua pesquisa não estão tendo acesso à Língua Brasileira de Sinais da mesma forma que os demais respondentes. 
A pesquisa chama atenção para a temática racial na sobreposição de trajetórias, que implica, inclusive no acesso às políticas públicas direcionadas às pessoas surdas. É o caso, por exemplo, da vulnerabilidade linguística que as pessoas surdas negras demonstraram na pesquisa, apresentando um nível de língua precário. Esse seria um problema produzido pelo efeito de subinclusão, uma vez que, segundo os dispositivos legais de acessibilidade linguística para surdos, a questão da comunicação seria relativa aos surdos de modo geral. No entanto, a diferença de desempenho linguístico observada demonstra, conforme Buzar (2012), a dificuldade de acesso, inclusive, a direitos voltados para surdos e a subordinação a condições existenciais precárias em todas as esferas sociais.

O autor ressalta que em São Luis existe uma presença firme de associações de surdos e de movimentos negros. No entanto, o debate das relações raciais na comunidade surda ainda seria muito incipiente; possivelmente devido a precauções contra uma possível fragmentação que tal abordagem poderia desencadear. Buzar (2012) considera que, não obstante ter sido fundamental para o desenvolvimento da luta por direitos, inicialmente, terse criado uma unidade; atualmente, seria necessário redimensionar a luta, considerando que o movimento é composto por diferentes grupos, cujas particularidades devem ser parte da pauta, para que assim políticas públicas específicas possam ser desenvolvidas em prol dos surdos mais vulnerabilizados.

Verificou-se que os surdos negros sofrem preconceito tanto dentro das comunidades surdas quanto na sociedade em geral. Em suas narrativas emergiram inúmeros relatos de discriminação racial entre surdos e diversas dificuldades de relacionamento com outras pessoas, mesmo no contexto familiar, educacional ou social, sendo saliente a ausência de parceiros amorosos. Revelou-se ainda a relação de maior proximidade dos ouvintes com surdos brancos, contrariamente ao afastamento em relação a surdos negros, conforme os depoimentos. Uma pessoa surda negra afirmou que ser surdo é possível de se absorver, mas ser negro seria, segundo o depoimento, muito pior do que ser surdo.

Finalmente, o estudo alerta para a dificuldade de percepção do racismo sofrido, atribuindo-se, por conseguinte, a discriminação à surdez.

\section{Os Surdos Negros na Contemporaneidade}

Ainda em 2012, outra pesquisa em nível de mestrado na área da Educação é desenvolvida por Furtado na Universidade Federal do Rio Grande do Sul, tendo como título 


\section{DOI: $10.5902 / 198468628229$}

Narrativas Identitárias e Educação: os Surdos Negros na Contemporaneidade, que no ano de 2015 foi publicada em livro pela editora Prismas.

A pesquisa de Furtado (2012) tem o objetivo de investigar questões referentes à dupla diferença e seus significados, a partir de narrativas de surdos negros. As análises são realizadas com o aporte teórico de autores como Amaral (2004, 1998), Lobo (2008), Skliar (2005), Gallo (2005), Rodrigues (2008) etc.

A fim de conhecer como os surdos negros se narram, é realizada uma análise dos perfis dos alunos do Curso de Licenciatura em Letras-LIBRAS, turma 2008, no espaço virtual. Não fica clara a quantidade de perfis analisada, tampouco se foi de uma turma específica. São também realizadas dez entrevistas, sendo nove presenciais e uma à distância, via mensagens eletrônicas por escrito; duas outras entrevistas foram feitas oralmente e as demais em LIBRAS com intermediação de intérprete. O registro dos encontros deu-se por meio de filmagens e posterior transcrição. O grupo de dez surdos negros compunha-se de dois alunos do Letras-LIBRAS e oito alunos de EJA ${ }^{8}$ de escolas de surdos localizadas em Porto Alegre. Não é feita menção à faixa etária.

Em virtude dos estereótipos existentes em relação aos surdos e em relação aos negros - nos quais tanto os surdos como os negros são concebidos como sujeitos inferiores, limitados intelectualmente, com tendência à criminalidade (negros), considerados deficientes e incapazes (surdos) - concebe-se os surdos negros como sujeitos "duplamente diferentes" (FURTADO, 2012). Além disso, a autora assume que a cultura surda é plural, constituída por grupos com peculiaridades distintas, como os surdos homossexuais, as mulheres surdas, os surdos negros, entre tantas outras peculiaridades existentes no interior das comunidades surdas.

Os surdos negros entrevistados durante a pesquisa de Furtado (2012) apresentam trajetórias diversas de vida: alguns frequentaram exclusivamente escola de surdos, outros estudaram muito tempo em escola comum e apenas tardiamente foram para a escola de surdos; mostram diferentes situações socioeconômicas e diferentes contextos familiares. Sendo assim, tais sujeitos narram-se em função de suas vivências.

Furtado (2012) pontua que a maioria dos surdos negros entrevistados durante a pesquisa afirma não ter passado por situações de preconceito evidente em razão da dupla diferença, embora haja aqueles que relatem o oposto. Nos entrevistados que reconhecem

\footnotetext{
${ }^{8}$ Educação de Jovens e Adultos.
} 
DOI: $10.5902 / 198468628229$

a existência da dupla diferença, eles a entendem como divisível, ou seja, negritude e surdez não constituiriam uma unidade. Ora haveria preconceito em razão da negritude, ora em razão da surdez, ocorrendo de maneira dissociada, segundo eles.

Para os entrevistados, o preconceito relacionado à surdez seria mais frequente do que o preconceito racial e ambas as formas de preconceito variariam conforme as circunstâncias: quando estão entre os ouvintes são discriminados por serem surdos; já entre os surdos, por serem negros. Um surdo entrevistado relatou que em escola regular sofreu preconceito em função da surdez, uma vez em escola de surdos sofreu preconceito por não dominar a língua de sinais. Outro entrevistado relata que quando não utiliza LIBRAS no espaço público, é identificado somente como negro e vivencia o preconceito racial. No entanto, desde o momento em que é percebido como surdo, o preconceito aumenta. Segundo ele, o "negro ouvinte tem um problema e o surdo negro tem dois" (2012, p. 77).

Com relação aos perfis dos alunos no espaço virtual do curso de Letras-LIBRAS 2008, todas as apresentações são iniciadas com a identificação da surdez, os alunos postam dados que consideram relevantes sobre si, sendo recorrentes as narrativas relacionadas à formação acadêmica e atuação profissional; sem menção à raça. Sendo assim, a pesquisadora afirma que, possivelmente, haveria surdos negros, não sendo possível, porém, identificá-los através do perfil. A organização de dados relevantes na composição do perfil pode ter sido pautada pelo contexto de interação, segundo Furtado (2012), no qual a maioria dos alunos é surda e envolve formação acadêmico-profissional na área da língua de sinais. Assim, essa forma de apresentação demonstraria pertencimento à comunidade surda. No entanto, a autora não informa se nos perfis do ambiente virtual haveria foto dos estudantes por meio da qual talvez fosse possível identificar alunos negros.

Furtado (2012) conclui, a partir dos dados da pesquisa, que a surdez é encarada como a identidade principal pelos entrevistados, uma vez que estes expressam orgulho em compartilhar uma língua, uma história de lutas e de conquistas com outros surdos. A experiência de ser duplamente diferente é distinta para cada um dos sujeitos entrevistados. Existindo, no entanto, conforme se apurou, um predomínio do discurso acerca da identidade surda, evidenciando o sentimento de pertença à comunidade surda, de compartilhamento de uma língua comum, de costumes e de vivências, o que não foi evidenciado em relação à identidade negra. Esta, de modo geral, teria sido minimizada, mesmo entre os participantes que reconhecem a existência de uma dupla diferença. Deles, apenas um 


\section{DOI: $10.5902 / 198468628229$}

participa do Movimento Negro, envolvendo-se nos debates da surdez e da negritude em todo o Brasil.

\section{Relações entre surdez, raça e gênero}

Em 2015, Vedoato desenvolve uma pesquisa em nível de mestrado na área da Educação pela Universidade Estadual de Londrina, com o título Relações entre surdez, raça e gênero no processo de escolarização de alunos surdos do Paraná. A pesquisa teve por objetivo analisar as relações entre surdez e as condições de raça e gênero no processo de escolarização de alunos surdos do Estado do Paraná, por meio de duas estatísticas públicas, a saber: os dados oficiais de matrícula do Censo da Educação Básica de 2013, coletadas e divulgadas pelo Instituto Nacional de Estudos e Pesquisas Educacionais Anísio Teixeira (INEP) e os dados demográficos de 2010 do IBGE sobre incidência da população surda, segundo frequência à escola no Brasil e no Paraná.

A pesquisa considerou os dados referentes à categoria não consegue de modo algum para a deficiência auditiva e trabalhou com os dados referentes à faixa etária entre 0 e 19 anos, em virtude de ser uma população em idade escolar. Os dados foram agregados por: (1) Modalidade; (2) Raça; (3) Sexo. As análises de Vedoato (2015) indicaram que as condições de acesso e de permanência do aluno surdo na educação básica paranaense são impactadas não só pela condição da surdez, mas também pela cor ou raça e pelo gênero.

Finalmente o estudo argumenta que a surdez, não obstante ser uma marca indelével, não constitui exclusivamente o sujeito, de modo, a torná-lo exclusivamente surdo. Outras marcas presentes o constituem e podem concorrer para impactar suas condições de vida e de escolarização. Sendo assim, as condições de escolarização do aluno surdo, homem e branco são mais favoráveis que as da aluna surda, mulher, preta ou parda. Com isso, conclui-se que apesar de as condições de escolarização da pessoa surda serem precárias, quando associadas a outras marcas sociais, como gênero e raça, tal precariedade tende a se intensificar.

\section{Outras pesquisas localizadas}

Em 2013, a Revista de Ciências da Educação, da UNISAL (Centro Universitário Salesiano de São Paulo) publica um trabalho cujo título é Surdo-negro soteropolitano: uma 
DOI: $10.5902 / 198468628229$

pesquisa exploratória sobre a sua percepção de opressão e exclusão de Alex Pereira e Rosenilde Pereira.

Os autores pontuam que a abordagem da duplicidade dos estigmas da deficiência e étnicos-raciais é ainda muito tímida nos debates acadêmicos sobre a surdez. A pesquisa objetivou analisar a opressão e a exclusão vivenciadas por adolescentes surdos negros soteropolitanos a partir de entrevistas semi-estruturadas feitas com vinte e um alunos surdos, brancos e negros, sendo treze de $8^{a}$ série de escola de surdos, em que oito são homens e cinco são mulheres; e oito alunos do $1^{\circ}$ ano de uma escola inclusiva, sendo cinco homens e três mulheres. Ambas as escolas situam-se na região metropolitana de Salvador, na Bahia.

Pretendeu-se ainda captar a percepção dos alunos surdos acerca da presença de sentimentos de racismo em três níveis: individual, institucional e cultural. As perguntas foram feitas em português escrito e traduzidas para a LIBRAS, com o auxílio de uma intérprete. As respostas foram dadas individualmente em LIBRAS e traduzidas para 0 português pela intérprete.

O racismo no nível individual revelar-se-ia nas relações interpessoais, em que o membro de um grupo racial julga-se superior em relação a outro indivíduo cujo pertencimento racial seja distinto do seu. No nível institucional, instituições como: Estado, escola, igrejas, empresas e partidos políticos reproduzem e atualizam o racismo em diversas esferas sociais por meio de mecanismos de manutenção de poder. No nível cultural, o racismo expressar-se-ia na cultura por meio da legitimidade atribuída a saberes produzidos por determinados grupos raciais e não por outros.

$\mathrm{Na}$ análise dos dados, o sentimento de preconceito racial, no nível individual, revelouse na quase totalidade das respostas. Na percepção dos sujeitos surdos negros da pesquisa, o sentimento de preconceito racial é citado como sendo observado no distanciamento por parte das pessoas e na ausência de carinho por partes dos familiares. Em contrapartida, esse suposto distanciamento não foi relatado pelos surdos brancos entrevistados. Os relatos dos surdos negros sobre conquistas amorosas, por sua vez, apontaram para a existência de preterimento em relação a surdos brancos.

No nível do racismo institucional, os sujeitos surdos negros relatam que, de forma sistemática, em diversos espaços sociais, como shopping, meios de transporte público, escola e em família, existe uma diferença de tratamento perceptível, conforme a cor da pele: "Algumas crianças negras e surdas apanham muito. Quando é branca, todo mundo 
DOI: $10.5902 / 198468628229$

abraça, carrega; quando é preta não, despreza (L. M. 17 anos, 9ำ ano, surdo-negro)"; "Às vezes o próprio pai quando o filho é negro despreza (S. 18 anos, 9o ano, surdo-negro)" (PEREIRA e PEREIRA, 2013, p. 7). Ainda no nível institucional, segundo os autores do estudo, os alunos da escola de surdos, em sua maioria, percebiam-se negros. Em contrapartida, os alunos surdos da escola inclusiva apresentavam dificuldade na percepção de si como surdos negros. Do ponto de vista cultural, percebeu-se que os entrevistados não participam de movimentos sociais negros, cuja existência lhes era, inclusive, desconhecida. Por outro lado, não foi mencionado se, em oposição, eles participariam de movimentos surdos.

Finalmente, os autores sinalizam para a necessidade de aprofundamento do estudo, incluindo sujeitos surdos negros na elaboração, execução e construção de instrumentos de pesquisa como parte indissociável do processo de tomada de consciência. Além disso, apontam a necessidade de enfrentamento coletivo pela via da convergência de perspectivas de lutas nos movimentos surdo e negro, visto que a somatória de estigmatizações e preconceitos potencializaria e fortaleceria os efeitos de opressão e de exclusão, interagindo de maneira sinérgica e desencadeando, assim, conforme os autores, uma dupla jornada de enfrentamento social e, por conseguinte, maior desvantagem social e educacional ao indivíduo.

O último trabalho localizado até o momento $S u r d e z$ e racialidade: identidades em diálogo no espaço escolar? de Viviane Miranda (2017), constituiu-se em uma pesquisa bibliográfica, publicada no ํㅡ 33 da Revista da Fundarte, cujo objetivo foi relacionar surdez e racialidade na perspectiva dos Estudos Culturais a partir da categoria interseccionalidade

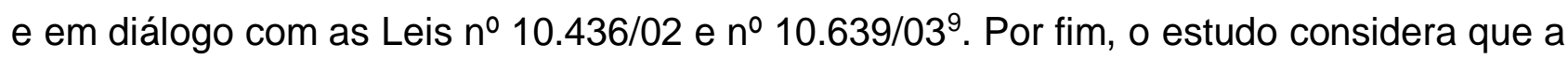
sobreposição da surdez sobre outras determinações sociais, como a raça, acaba produzindo diferentes assimetrias e afetando, desproporcionalmente, as pessoas surdas; além de ter o efeito de simplificação da complexidade das identidades surdas interseccionais e o silenciamento de suas necessidades específicas.

\footnotetext{
${ }^{9}$ Lei que institui a obrigatoriedade do ensino de conteúdos referentes à História e à Cultura AfroBrasileira no âmbito de todo o currículo escolar, em especial nas áreas de Educação Artística, Literatura e História Brasileiras, nos estabelecimentos de ensino fundamental e médio, oficiais e particulares.
} 


\section{Considerações finais}

DOI: $10.5902 / 198468628229$

A intenção deste artigo foi realizar um levantamento bibliográfico com o desafio de mapear a produção acadêmica da área, isto é, apresentar as escassas pesquisas cuja constituição do objeto fosse surdez e raça. Intentou-se ainda divulgar uma área de pesquisas que pode ser mais explorada. Afinal, é necessário conhecer o que já foi feito e produzido para que novos estudos possam vir a enriquecer esse campo com trabalhos cada vez mais rigorosos do ponto de vista teórico e metodológico.

Foram localizadas ainda duas teses de doutorado cujos objetos, de certa forma, tangenciam nosso tema, sendo uma de 2016 e outra de 2017; ambas da Pontifícia Universidade Católica de São Paulo (PUC), do departamento de Educação, do Programa de Estudos Pós-Graduados em Educação: História, Política, Sociedade e orientadas por José Geraldo Silveira Bueno.

A tese de Michelle Melina Gleica Del Pino Nicolau Pereira cujo título é Deficiência, raça e gênero: análise de indicadores educacionais brasileiros, defendida em 2016, não aborda especificamente a surdez. O estudo analisa os indicadores educacionais de pessoas com deficiência, em relação a gênero e raça, utilizando como fontes de coleta de dados o Censo Demográfico do IBGE de 2010, sobre a incidência populacional, e o Censo Escolar de 2012 (MEC ${ }^{10}$, INEP) referente às matrículas de alunos com deficiência visual, auditiva, física e intelectual no ano de 2012, na Educação Básica, por tipo de escolarização e etapa de ensino, em âmbito nacional e distribuídas pelas regiões geográficas.

Já a tese de Carla Cazelato Ferrari Surdez, cultura e identidade: as trajetórias sociais na construção das identidades de indivíduos surdos é de 2017 e não aborda especificamente a categoria raça, mas classe social a partir de Bordieu. A pesquisa tem como finalidade compreender de que forma vinte e quatro pessoas surdas, considerando suas distintas condições sociais objetivas, desenvolveram suas identidades sociais, tendo como parâmetro de diferenciação sua decisão em utilizar preferencialmente a língua oral ou a língua de sinais.

Ambas as teses não abordam afetivamente a correlação entre surdez e raça, entretanto, de certa forma tangenciam o tema visto que uma fala de deficiência, incluindo a surdez, correlacionada com raça e gênero (PEREIRA, 2016) e a outra correlaciona surdez com classe social (FERRARI, 2017), incluindo raça.

\footnotetext{
${ }^{10}$ Ministério da Educação e Cultura.
} 
DOI: $10.5902 / 198468628229$

Dessa forma, evidencia-se que apesar de a produção acadêmica na área da surdez ter aumentado e se diversificado nos últimos anos (PAGNES e SOFIATO, 2014), o mesmo não se verificou em relação às pesquisas acerca de surdez/raça. Constata-se uma escassez na produção acadêmica brasileira a respeito do tema. Dado surpreendente, por um lado, visto que a população negra brasileira, especificamente no grupo de pessoas com deficiência auditiva, conforme o último Censo do IBGE (2010), não se apresenta numericamente insignificante. E, por outro lado, não tão surpreendente, visto que existe uma produção acadêmica expressiva referente a surdez sendo realizada na Região Sul; e, de acordo com dados do último Censo do IBGE, essa é a Região com os menores percentuais de pretos e pardos, $76 \%$ da população residente nessa região é branca. Pela apresentação dos autores das três principais pesquisas localizadas foi possível notar que a trajetória da pesquisadora ou do pesquisador pode contribuir significativamente na sacação (FURTADO, 2012) de seu objeto, na definição de suas perguntas.

É interessante também observar que a academia deve estar atenta aos movimentos sociais visto que estes podem trazer novas perguntas para velhos problemas e, assim, contribuir com a definição de outros recortes de fenômenos da realidade social. Em 2008 foram encetadas em São Paulo as primeiras discussões organizadas, de que se têm notícias até o momento, no interior do movimento social surdo acerca da inclusão social do negro surdo. Esse movimento articulou-se no seio da comunidade surda e em pouco tempo passou de um evento localizado e pontual a um movimento nacional, organizado formalmente. Não foram localizadas pesquisas até a presente data a respeito da dinâmica desse movimento, esquematizado na Tabela 1.

As três pesquisas mais relevantes apresentadas (BUZAR, 2012; FURTADO, 2012 e VEDOATO, 2015) não tiveram continuidade na exploração da área em outros níveis de pesquisa. Sendo assim, a correlação entre surdez e raça pode ser mais explorada na produção acadêmica brasileira, em diferentes modalidades, áreas de concentração e referenciais teóricos. A intenção deste trabalho também foi essa: despertar interesse relativo ao tema. 
Referências

DOI: $10.5902 / 198468628229$

BRASIL. Decreto 5.626, 22 de Dezembro de 2005. Regulamenta a Lei no 10.436, de 24 de abril de 2002, que dispõe sobre a Língua Brasileira de Sinais - Libras, e o art. 18 da Lei $n^{\circ}$ 10.098, de 19 de dezembro de 2000.

BRASIL. IBGE. Censo Demográfico 2010: Características Gerais da População, Religião e Pessoas com Deficiência. ISSN 0104-3145. Censo demogr. Rio de Janeiro, p.1-215, 2010.2 Disponível em: <biblioteca.ibge.gov.br/visualizacao/periodicos/94/cd_2010_religiao_deficiencia.pdf>. Acesso em 03 de janeiro de 2018.

BRASIL. Lei n.10.436, de 24 de Abril de 2002. Dispõe sobre a Língua Brasileira de Sinais - Libras e dá outras providências.

BRITO, Fábio Bezerra de. O movimento social surdo e a campanha pela oficialização da língua brasileira de sinais. 2013. 275 f. Tese (Doutorado) - Faculdade de Educação, Universidade de São Paulo, São Paulo, 2013.

BUENO, José Geraldo Silveira. Surdez, linguagem e cultura. In: Cadernos CEDES, São Paulo, n. 46, 1998.4 Disponível em <www.scielo.br/scielo.php?script=sci_arttext\&pid=S0101-32621998000300005\#1not>. Acesso em 22 de julho de 2017.

BUZAR, Francisco José Roma. Interseccionalidade entre raça e surdez: a situação de surdos (as) negros (as) em São Luís - MA. 2012. 155 f., il. Dissertação (Mestrado em Educação) - Universidade de Brasília, Brasília, 2012.

DORZIAT, Ana. Bilinguismo e Surdez: Para Além de Uma Visão Linguística e Metodológica in SKLIAR, Carlos (Org.). Atualidade da Educação Bilíngue para Surdos: Processos e Projetos pedagógicos. Vol. 1. Porto Alegre: Mediação, 1999.

FERRARI, Carla Cazelato. Surdez, cultura e identidade: as trajetórias sociais na construção das identidades de agentes surdos. Tese (Doutorado) - Programa de estudos Pós-graduados em Educação: História, Política, Sociedade, Pontifícia Universidade Católica de São Paulo, 2017. 
FURTADO, Rita Simone Silveira. Narrativas Identitárias e Educação: os Surdos Negros na Contemporaneidade. 2012. 122 f. Dissertação (Mestrado em Educação) Universidade Federal do Rio Grande do Sul, Porto Alegre, 2012.

GARCIA, Barbara Gerner de. O Multiculturalismo na Educação dos Surdos: a Resistência e Relevância da Diversidade para a Educação dos Surdos in SKLIAR, Carlos (Org.). Atualidade da Educação Bilíngue para Surdos: Processos e Projetos pedagógicos. Vol. 1. Porto Alegre: Mediação, 1999.

GOLDENBERG, Mirian. A arte de pesquisar: como fazer pesquisa qualitativa em ciências sociais. $8^{\mathrm{a}}$ ed. - Rio de Janeiro: Record, 2004.

MIRANDA, Viviane Marques. Surdez e racialidade: identidades em diálogo no espaço escolar? Revista da Fundarte, Montenegro, ano 17, n. 33, p.39-69, jul/dez. 2017. Disponível em: <seer.fundarte.rs.gov.br/index.php/RevistadaFundarte/index>.

PAGNEZ, Karina Soledad; SOFIATO, Cássia Geciauskas. O estado da arte de pesquisas sobre a educação de surdos no Brasil de 2007 a 2011. Educ. rev. [online]. 2014, n. 52, pp.229-256. ISSN 0104-4060. http://dx.doi.org/10.1590/0104-4060.33394.

PAIXÃO, Marcelo. Múltiplos de desigualdades: análise preliminar dos indicadores dos brasileiros portadores de necessidades especiais e a sua desagregação pela variável raça/cor. Espaço (INES), Rio de Janeiro: INES, n. 24, p. 55-67, 2005. Disponível em $<$ drive.google.com/file/d/0BwAEnJAISYTTcINtR3NuV054ZVU/view>. Acesso em 17 de julho de 2017.

PEREIRA, Alex Sandrelanio dos Santos; PEREIRA, Rosenilde Oliveira. Surdo-negro soteropolitano: uma pesquisa exploratória sobre a sua percepção de opressão e exclusão. In REVISTA DE CIÊNCIAS DA EDUCAÇÃO, Americana, Ano XV, v. 02, n. 29, p. 139-148, jun-dez 2013. Disponível em $<$ www.revista.unisal.br/ojs/index.php/educacao/article/viewFile/292/261 >. Acesso em $17 \mathrm{de}$ julho de 2017.

PEREIRA, Michelle Melina Gleica Del Pino Nicolau. Deficiência, raça e gênero: análise de indicadores educacionais brasileiros. Programa de estudos Pós-graduados em Educação: História, Política, Sociedade. Pontifícia Universidade Católica de São Paulo, 2016. 
DOI: $10.5902 / 198468628229$

SKLIAR, Carlos. Os Estudos Surdos em Educação: Problematizando a Normalidade in SKLIAR, Carlos (org.). A surdez: um olhar sobre as diferenças. Porto Alegre: Mediação, 2005, 3ㄹ. ed.

VEDOATO, Sandra Cristina Malzinoti. Relações entre surdez, raça e gênero no processo de escolarização de alunos surdos do Paraná. 2015. 66 f. Dissertação (Mestrado em Educação) - Universidade Estadual de Londrina, Londrina, 2015.

\section{Correspondência}

Viviane Marques Miranda - Universidade Nove de Julho (UNINOVE). Av. Dr. Adolpho Pinto, 109 - Barra Funda, CEP: 01156-050, São Paulo, São Paulo, Brasil.

Th is work is licensed under a Creative Commons Attribution-NonCommercial 4.0 International (CC BY-NC 4.0) 